\title{
Proactive Behavior, Leader-Member Exchange and Innovative Work Behavior among Employees of Software Houses
}

\author{
Aisha Zubair* and Naeem Aslam \\ National Institute of Psychology, Quaid-i-Azam University, Islamabad, Pakistan \\ Email of corresponding author: aishazubair@nip.edu.pk
}

\begin{abstract}
Much of the recent literature on organizational behavior and psychology provides evidence that proactive behavior and leader-member exchange would be contributory factors of innovative work behavior. Somewhat surprisingly, very limited attention has been devoted to the significant role that innovative work behavior played in organization. Thus, the present study aimed at examining the relationship of proactive behavior, leader-member exchange, and innovative work behavior among employees of software houses. The sample comprised of 500 employees, including both men and women from different private sector software houses of Federal city. Proactive Behavior Scale (Seibert, Kraimer, \& Crant, 2001), Leader-Member Exchange-7 Questionnaire (Schriesheim, Neider, Scandura, \& Tepper, 1992), and Innovative Work Behavior Scale (Janssen, 2000) were used to assess the research framework. Results showed significant positive relationship between proactive behavior and leader-member relations. Similarly, proactive behavior and leader-member relations were positively associated with innovative work behavior. It was also found that employees with higher level of education and extended work experience exhibited better proactive behavioral tendencies, leader-member relations, and innovative work behavior. Future research directions and implications of the study were also discussed.
\end{abstract}

Keywords: Proactive Behavior; Leader-Member Exchange; Innovative Work Behavior; Software Houses; Employees.

\section{INTRODUCTION}

Due to the increasing importance attached to innovative behavior at workplace, more focus is placed on the interplay of personal and organizational factors in determining the creative output of employees. Consequently, innovative work behavior has been the interest of both academicians (e.g., Suhaimi \& Panatik, 2016) and practitioners (e.g., Li, Wang, Gao, \& Yu, 2015) in the past decade. In the extant literature, many scholars have theoretically and empirically investigated the determinants of innovative work behaviors and how it is shaped by employees' work attitudes and leadership patterns. Numerous studies (see Lo, Ramayah, \& Run, 2009; Taştan \& Davoudi, 2015) have shown that individual styles along with managerial practices of the leaders are effective predictors of job satisfaction, organization commitment, moral identity, creativity, and organizational citizenship behavior. Generally, the prior researches focused on the cognitive aspect of innovative behavior and linked personal traits of employees (Bergeron, Schroeder, \& Martinez, 2014) as the major determinants of generating creativity at workplace. Other studies (Bernerth, Walker, \& Harris, 2015; Collins, 2007; Lunenburh, 2010) predominantly focused on the exclusive models of leadership such as transformational, transactional, and authentic leadership; however, less attention has been paid to the role of leader member relations which may influence the desired occupational outcomes (e.g., job performance, creativity, and innovation). In addition, empirical investigations have specifically focused on task related novelty specifically in engineering and mechanical based job; nonetheless, literature is relatively silent about the role of generic aspect of personality (such as proactive behavior) and its confluence with leader-member relations on employees' task related performance, especially innovative work behavior that calls for more creativity and contributes much to organization innovation, effectiveness, development, and survival (Chen, 2011; Frese, Garst, \& Fay, 2007; Gan \& Chenug, 2010). In the process of generating, promoting and implementing the new ideas, processes or procedures, individual would face so many risks, difficulties, conflicts, and even ethical dilemmas, this indicates that relations with the leader either facilitate or inhibit the 
creative expressions at workplace (Kheng, June, \& Mahmood, 2013). In the extant researches, proactive behavior and leader-member exchange were mainly identified as constructs at individual level. However, with the development of multilevel technique, scholars shift their attention to the multilevel construct exploration and examination. Concerning proactive behavior, more and more scholars proposed that personality is more than individual trait in the sense that it could be the malleable process that referred to the collective belief about the leaders' traits and behaviors and recommended to examine the impacts of leadership at multiple levels (e.g., Cropanzano \& Mitchell, 2005).

\section{PROACTIVE BEHAVIOR}

Employee proactive behaviors are "selfdirected and future-focused actions in an organization in which the individual aims to bring about change"' (Janssen, 2000, p. 287). From early studies on proactivity until recently, it is associated with effecting environmental change (Crant, 2000) and having an impact on the work environment (Grant \& Ashford, 2008). Behaviors such as feedback seeking (Altunoğlu \& Gürel, 2015), issue selling (Gan \& Chenug, 2010), expressing voice (Frese et al., 2007), individual initiative in pursuing goals (Lo et al., 2009), taking charge (Li et al., 2015) and problemsolving and idea implementation (Bergeron et al., 2014) are considered proactive. Their importance is recognized by researchers, who have examined various proactivity-related constructs to understand their antecedents (Fuller \& Marler, 2009). Conventionally, industrial researchers placed great emphasis on the job characteristics that facilitates the employee adherence to his/her job (Grant \& Ashford, 2008); however, Crant (2000) described four constructs related to proactive behavior including proactive personality, personal initiative, role breadth selfefficacy, and taking charge. Therefore, proactive employees make rigorous efforts to adapt in accordance to the culture of organization and behave vigorously to change characteristics of the job in order to make better adjustment at workplace (Frese et al., 2007). Proactivity of the employees is reflected through their active behavior in redefining their goals that are assigned by their organization (Fuller \& Marler, 2009); while, proactive behavior of employees is usually expressed in terms of self directed actions to alter the work environment leading to productive outcomes such as introducing latest techniques, effective strategies to perform routine tasks, and even convincing their leader to work out for efficient mechanisms for developing networks with their followers (Gan \& Chenug, 2010).

\section{LEADER-MEMBER EXCHANGE}

Leader-member exchange (LMX; Alsughayir, 2017) model basically originated from Vertical Dyad Linkage theory (Dansereau, Yammarino, \& Markham as cited in Lunenburg, 2010) emphasized that major dynamics of the leadership are expressed in terms of communication and relation between leaders and their followers. From the perspective of social exchange theory (Cropanzano \& Mitchell, 2005), a basic tenet of which is that individuals provide benefits to other individuals in the expectation that they will receive equivalent-value benefits in return. According to Altunoğlu and Bulgurcu-Gürel (2015), LMX is described as the social exchange between subordinates and higher-ups of both tangible and intangible resources, clearly identifies the different types of relationships that leaders have with individual employees. Moreover, LMX is seen as a good exchange where the leader renders certain benefits such as work guidance, technical support, significant rewards, and the followers respond by reciprocating through respect for leader, collaboration, devotion to the work, and excellent performance (Bernerth, Walker, \& Harris, 2015). LMX model further assumes that leaders and followers are likely to vary in the exchange type that would influence the relations between them (Alsughayir, 2017). For instance, the type of relations between the leader and individual followers can shape the formation of in-groups and out-groups; where an in-group constitutes of those members that have more and valuable exchanges with the leader, while out-group members have lower interactions with the leader. 


\section{INNOVATIVE WORK BEHAVIOR}

Innovative work behavior is a process of generating creative and potentially useful procedures to give a competitive edge to the organization as well as its employees. This would be achieved by the most effective products, services, processes, technologies or ideas on hand for the markets, governments and businesses (Kheng et al., 2013). De Jong and Den Hartog (2010, p. 23) defined innovative work behavior as "the intentional behavior of an individual to introduce and/or apply new ideas, products, processes, and procedures to his or her work role, unit, or organization." According to Prahalad and Ramaswamy (2012) organizations that have the capability to innovate are better able to gain sustainable competitive advantage over their competitors. Innovative work behavior is generally conceptualized within the framework of personal attributes as well as contextual (organizational) factors (Agarwal, 2014). Employees usually express their innovative development through cognitive and physical activities and engage in the sequential process of developing, testing, and modifying the ideas.

\section{THEORIZATION OF HYPOTHESES: LITERATURE REVIEW}

Numerous studies highlighted the role of proactive behavior of leader and employees that play pivotal role in generating desirable work behaviors. For instance, Chen (2011) and Tastan (2013) declared that employees who possess proactive behavior have probably developed better relationship quality with their leaders because of their own initiative and work performance. Moreover, organizations do not directly control proactive behavior rather they encourage the initiatives taken by employees to be actively involved in making changes and adaptations in the existing work mechanisms (Suhaimi \& Panatik, 2016); developing better social ties with their leaders (Bernerth et al., 2015); which subsequently resulted in productive work outcomes such as enhanced job performance, job satisfaction (Kheng et al., 2013), organizational commitment, and creative work output (Yuan \& Woodman, 2010).

Relationship building of employees with their supervisors is a vital part of proactive behavior, as the leader has direct role to effect career success of his/her subordinates (Prahalad \& Ramaswamy, 2012). Proactive employees are usually engaged in such work behaviors that goes beyond formal role expectations and job requirements given a hopeful culture rather than just accepting present working methods (Bergeron, Schroeder, \& Martinez, 2014). Studies that explored organizational product and procedures innovation, have conclusively inferred that proactive individuals who participated in organizational improvement projects and perform charged behavior have shown more inspiration for new and useful ideas and thoughts that promote excellent innovative performance ( $\mathrm{Li}$, Wang, Gao, \& Yu, 2015). Employees having quality relationships with their leaders are considered to be more innovative and creative because of their more initiative approach to challenging and difficult tasks (Taştan \& Davoudi, 2015). It has also been found that employees with high-quality LMX relationships receive more task related identification, interpersonal support, and positive reception (Tastan, 2013). The derivations of the aforementioned literature provide the basis to propose the following hypothesis:

\section{H1. Proactive behavior positively predicts} favorable leader-member exchange and innovative work behavior among employees of software houses.

Social exchange theorists (Altunoğlu \& Bulgurcu-Gürel, 2015; Bernerth et al., 2015; Suhaimi \& Panatik, 2016) propose that the relationship quality between supervisor and subordinate in LMX model may lead to several employee related outcomes. These outcomes include job satisfaction, agreement with the supervisor, better performance, commitment, and lowered turnover intentions. Successful leaders also facilitate and promote the employees; hence problems are always identified, new ideas and solutions are applied; and support is created for the new ideas and solutions to reflect innovative work behavior (Schyns, Paul, Mohr, \& Blank, 
2005). The congruence effect of leader and followers' proactive behavior enhances the quality of leader-member exchange which in turn influences the followers' job satisfaction, affective commitment, and job performance (Seibert, Kraimer, \& Crant, 2001).

Several studies inferred that innovative work behavior is not exclusively determined as a part of personality trait rather it is a composite of cognitions and behaviors that are formed mainly by the organizational situations ( $\mathrm{Li}, \mathrm{Gao}$, Wang, $\& \mathrm{Yu}, 2016)$. In this regard, proactive behavior of the employees play an important role in developing quality relations with the leader as well as reflecting creativity and innovation at work (Tastan, 2013). Leaders vary in the extent to which they typically display consulting, delegating and monitoring behavior and these practices are likely to have an impact on both employees' idea generation and application behavior. Additional set of studies (Akram \& Haider, 2016; Lunenburg, 2010) also concluded that leaders trying to enhance individual innovation among their employees could attempt to consult them more often, ensure that employees have sufficient autonomy in deciding how to go about their task, and support and recognize people's initiatives and innovative efforts. On the basis of these empirical evidences, we propose the following hypothesis:

H2. Highly educated employees would display elevated proactive behavior, better leadermember exchange, and augmented innovative work behavior as compared to employees with lesser education level.

H3. Employees with extended job experience are more likely to reflect increased proactive behavior, better leader-member relations, and elevated levels of innovative work behavior as compare to employees with lesser job experience.

The present study incorporated employees of software houses as these organizations are involved in the process of developing software by researching, testing, and implementing soft wares to meet diverse needs of the users. With the advent of new technology and fast growing software development, creativity and generating realistic innovative ideas is the important factor for software engineers to increase their productivity and compete with the products in the market (Akram \& Haider, 2016). With reference to local perspective, constant novelty and innovation are essential features for the existence of high-tech organizations such as software houses. Hence, the greater requirement of software houses would be employees with creative solutions as cognitively competent and resourceful personnel to transform the creative solutions into revenue generating and problemsolving technologies. Moreover, creativity and innovation have long been the brand features of software houses. Nevertheless, employees of software houses are experiencing extensive challenges both in terms of producing software products as well as designing those products. Equally important is the proactive and rigorous initiatives of the employees which also play a pivotal role in developing solutions and designing mechanism to achieve software solutions (Bergeron, Schroeder, \& Martinez, 2014). In addition, proactive behavior of the employees would bear an important role in psychological and emotional adjustment, regulation in new environment, and update with the new innovations in field of software. On the other hand, sound and healthy relations with the leaders serve as a foundation for the provision of technical support, guidance, and feedback which is imperative for the accomplishment of organizational goals as well as professional objectives of the employees.

The present study, therefore, would illustrate the following major objectives, that is, to explore the role of proactive behavior and leader-member exchange in innovative work behavior among employees of software houses. Additionally, it was also intended to investigate the role of various demographics (education and job experience) in relation to proactive behavior, leader-member exchange and innovative work behavior.

\section{METHOD}

\section{Sample}

A convenient sample comprising of regular employees $(\mathrm{N}=500)$ of private sector software houses was acquired from Rawalpindi and Islamabad. The respondents included both men (n $=263)$ and women $(n=237)$. Age of the employees ranged from 23 to 44 years $(\mathrm{M}=$ 
34.33; $\mathrm{SD}=7.99)$. Education level of the respondents included graduation $(\mathrm{n}=218)$, Masters ( $\mathrm{n}=150)$, and MS/M.Phil/Ph.D $(\mathrm{n}=$ 132). Overall work experience of the employees ranged from 1-8 years $(\mathrm{M}=5.28 ; \mathrm{SD}=3.33)$; while, job period in the present organization varied from minimum 1 to 5 years $(\mathrm{M}=3.53$; $\mathrm{SD}$ $=1.75)$. Job designation of the respondents included web developers / designers $(\mathrm{n}=149)$, software engineers $(\mathrm{n}=134)$, computer programmers $(\mathrm{n}=127)$, and system analysts / system integrators $(\mathrm{n}=90)$; while organization size of the software houses was on the average comprised of 22-25 employees.

\section{Measures}

Following three instruments which have been previously validated on Pakistani population were used in the present study.

Proactive Behavior Scale. Self-report measure of Proactive Behavior Scale (originally developed by Batmen \& Crant, 1993 having 17 items) which was later revised by Seibert et al. (2001) as a short version comprised of 10-items which was used in the present study, with reported $\alpha$ coefficient of .79 (Gan \& Cheung, 2010) and .83 (Bergeron et al., 2014). Responses were obtained on 5-point Likert scale ranging from (1) strongly disagree to (5) strongly agree. Possible score range was from 10-50 on the total scale, with high scores indicating more inclination for proactive behavior. In the present study, alpha coefficient of .84 was achieved for the Proactive Behavior Scale.

\section{Leader Member Exchange-7 Questionnaire (LMX-7)}

This scale developed by Schriesheim et al. (1992) comprising seven items was used to measure leader-member relations. All items were positively phrased to be rated on 5-point rating scale with response options ranging from (1) Not a bit to (5) A great deal and possible score could ranged from $7-35$ on total scale. Scores in the upper ranges indicate stronger, higher-quality leader-member exchanges (e.g., in-group members), whereas scores in the lower ranges indicate exchanges of lesser quality (e.g., outgroup members). Reported alpha coefficients of LMX-7 in the earlier literature were found adequately satisfactory such as .84 (Alsughayir,
2017), .86 (Bernerth et al., 2015), and .90 (Suhaimi \& Panatik, 2016); while for the present sample reliability coefficient of .78 was found for Leader Member Exchange-7 Questionnaire.

\section{Innovative Work Behavior Scale}

Self-report Innovative Work Behavior Scale (Janssen, 2000) was composed of 28 items and consisted of four subscales that is, Idea Generation (7 items), Idea Promotion (8 items), Idea Implementation (10 items), and Work Commitment (3 items). Respondents express their responses on 5-point Likert scale and the response options ranged from (1) Strongly Disagree to (5) Strongly Agree with potential score range of 28140 with cutoff score of 98 ; where higher score would indicate more tendencies of innovative behavior in work settings. Earlier evidence of alpha reliability for total Innovative Work Behavior Scale was reported as .94 and for subscales, alpha coefficients ranged from .76 to .87 (Li et al., 2016). In the present study alpha reliability for Innovative Work Behavior Scale was found to be .88 and for subscales ranged from .79 to .83 indicating the scale as dependable measure of the said construct.

\section{Procedure}

Formal permissions were acquired from the chief executives of respective software houses. Respondents were assured that this information would be used only for research purpose. After acquiring their informed consent, questionnaires were given to the employees and were briefed about the purpose of the research. Instructions were presented in written form on the questionnaires but brief verbal account was also narrated to the employees. Later, participants were cordially thanked for the provision of valuable information and data.

\section{RESULTS}

Regression analysis was conducted to determine the predictive role of variables; while, to investigate group differences, independent sample $t$-test and one way ANOVA was carried out.

Table 1 shows the regression analysis with proactive behavior and leader-member exchange 
Table 1: Step-wise Regression for Predictors of Innovative Work Behavior $(\mathrm{N}=500)$

\begin{tabular}{|lcccccccc|}
\hline Variables & $\boldsymbol{B}$ & $\boldsymbol{S E}$ & $\boldsymbol{\beta}$ & $\boldsymbol{p}$ & $\boldsymbol{R}^{\mathbf{2}}$ & $\boldsymbol{\Delta R}^{\mathbf{2}}$ & $\boldsymbol{F}$ & $\boldsymbol{p}$ \\
Step I & & & & & & & & \\
Constant & 40.59 & 6.93 & & & & & & \\
Age & .04 & .02 & & & & & & \\
Gender & .08 & .003 & & & & & \\
Proactive Behavior & .33 & .05 & .40 & .00 & .19 & .17 & 33.90 & .00 \\
Step II & & & & & & & & \\
Constant & 29.65 & 6.36 & & & & & & \\
Proactive Behavior & .18 & .05 & .28 & .01 & & & & \\
Leader-Member Exchange & .63 & .07 & .46 & .00 & .24 & .23 & 46.90 & .00 \\
\hline
\end{tabular}

Note. Age and gender are entered as controlled variables

Table 2: Differences on Educational Level of the Respondents in Relation to Study Variables $(\mathrm{N}=\mathbf{5 0 0})$

\begin{tabular}{|c|c|c|c|c|c|c|c|c|c|c|}
\hline \multirow[t]{2}{*}{ Variables } & \multicolumn{2}{|c|}{$\begin{array}{l}\text { Graduation } \\
\quad(n=218)\end{array}$} & \multicolumn{2}{|c|}{ Masters $(n=150)$} & \multicolumn{2}{|c|}{$\begin{array}{c}\text { MS/M.Phil/Ph.D } \\
(\mathbf{n}=132)\end{array}$} & \multirow[b]{2}{*}{$F$} & \multirow[b]{2}{*}{$p$} & \multirow[b]{2}{*}{$\eta^{2}$} & \multirow{2}{*}{$\begin{array}{c}\text { Tukey's } \\
\text { Post } \\
\text { Hoc }\end{array}$} \\
\hline & $M$ & $S D$ & $M$ & $S D$ & $M$ & $S D$ & & & & \\
\hline PB & 28.12 & 9.12 & 29.45 & 8.32 & 29.52 & 9.61 & 1.09 & .43 & - & - \\
\hline LMX & 24.1 & 8.90 & 29.23 & 9.52 & 32.37 & 8.10 & 14.61 & .00 & .11 & $\begin{array}{c}3>1,2 \\
2>1\end{array}$ \\
\hline IWB & 108.5 & 13.22 & 112.6 & 10.76 & 116.8 & 12.32 & 12.06 & .00 & .09 & $\begin{array}{c}3>1,2 ; \\
2>1\end{array}$ \\
\hline
\end{tabular}

Note. LMX = Leader-member exchange; PB = Proactive Behavior, IWB = Innovative work behavior.

Table 3: Differences on Job Experience in Relation to Proactive Behavior, Leader-Member Exchange and Innovative Work Behavior $(\mathbf{N}=\mathbf{5 0 0})$

\begin{tabular}{|lccccccccc|}
\hline Variables & $\mathbf{1 - 4}$ years $(\boldsymbol{n}=\mathbf{2 7 0})$ & $\mathbf{4 . 1 - 8}$ years $(\boldsymbol{n}=\mathbf{2 3 0})$ & \multicolumn{3}{c}{$\mathbf{9 5 \%}$ CI } & \multicolumn{2}{c|}{ Cohen's } \\
& $M$ & $S D$ & $M$ & $S D$ & $t(498)$ & $p$ & $L L$ & $U L$ & $d$ \\
PB & 30.79 & 6.51 & 36.28 & 7.39 & 8.55 & .00 & -7.43 & -1.53 & .61 \\
LMX & 23.72 & 8.28 & 29.26 & 9.10 & 9.51 & .00 & -6.74 & -1.32 & .88 \\
IWB & 103.87 & 13.31 & 108.80 & 14.76 & 7.18 & .00 & -16.49 & -2.39 & .73 \\
\hline
\end{tabular}

Note. PP = Proactive Behavior; LMX = Leader-member Exchange; IWB = Innovative Work Behavior

as predictor variables and innovative work behavior as outcome variable. Results indicated that proactive behavior and leader-member exchange are significant positive predictors of innovative work behavior. Leader-member exchange explained $23 \%$ variance in innovative work behavior; whereas $17 \%$ variance is accounted by proactive behavior in explaining innovative work behavior; hence, providing reasonable grounds in support of $\mathrm{H} 1$.
Results presented in Table $\mathbf{2}$ showed significant differences on education level of the employees across leader-member exchange and innovative work behavior. Findings indicated that employees with higher level of education showed better relations with their leaders and greater innovative work behavior as compared to the groups of employees having lesser level of education. However, non significant educational differences are observed on the construct of proactive behavior; thereby offering partial support for $\mathrm{H} 2$. 
Table 3 showed significant differences on varying levels of job experience across proactive behavior, leader-member exchange, and innovative work behavior. These findings suggest that employees with extended job experience expressed higher tendencies of proactive behavior, better leader-member exchange, and elevated levels of innovative work behavior; hence providing substantial support for $\mathrm{H} 3$.

\section{DISCUSSION}

The present research aimed to explore the proactive behavior, leader-member exchange and innovative work behavior among employees of software houses. Various demographics were also investigated along the study variables such as level of education and job experience.

Findings of the present study showed that proactive behavior was significantly related to leader member exchange and innovative work behavior. These findings can be best explained in the light of earlier evidences (Fuller \& Marler, 2009; Kheng et al., 2013) which have shown that employees with proactive inclinations tend to take rigorous initiatives in developing quality relations with their leaders in order to seek guidance and support from them. Moreover, the purpose of seeking advice and support from the leaders is to experiment with more unconventional, yet useful ideas at workplace (Zhang et al., 2012). Numerous studies (Kheng et al., 2013; Li et al., 2016; Schyns, Paul, Mohr, \& Blank, 2005) suggested that when employees join the organization, their behaviors focus on the organizational socialization, hence proactive behavior of employees predicted that it would also affect quality of leader-member relations. In addition, proactive behavior of the employees also buffers the relationship between organizational demands and innovative work behavior (Tastan, 2013). Likewise, additional set of studies (Bergeron et al., 2014; Crant, 2000; Li et al., 2016; Lo, Ramayah, \& Run, 2009) also inferred that proactive and positively inclined employees are motivated to develop and maintain a high-quality exchange relationship with their leaders and are able to outclass their contemporaries in terms of job performance and creative productivity.
Step-wise regression analysis determined the predictive role of leader-member exchange and proactive behavior in innovative work behavior. Prior empirical evidences (Agarwal, 2014; De Jong \& Den Hartog, 2010; Zhang et al., 2012) also provide support for the postulated assumption and found similar effect of leader and followers proactive behavior on leader-member exchange quality, which results in followers' job satisfaction, affective commitment, and job performance. Proactive employees are usually engage in such working behaviors that go beyond the formal role expectations and job requirements given a hopeful culture rather than just accepting present working methods (Bergeron et al., 2014). Findings of product innovation have often stressed on the proactive individuals who take part in organizational improvement projects and perform charged behavior, which is inspired to have new and useful ideas and thoughts that promote excellent innovative performance (Chen, 2011). Numerous studies (Bernerth, et al., 2015; Collins, 2007; Suhaimi \& Panatik, 2016) highlighted that being proactive, actively involved in one's work environment and certain that one is capable of thinking of novel ideas are the most important predictors of innovation.

Findings also indicated that employees with higher education level have expressed better leader-member exchange and innovative work behavior. These findings can be optimally explained from the perspective of Schyns et al. (2005) asserting that highly educated employees are more capable to develop active and positive exchange with their leader, and subsequent better expressions of novel and creative solutions. DeJong and Den Hartog (2010) further added that employees with better academic skills are able to understand the environmental and contextual requisites of optimal functioning; hence, they develop and sustain healthy relations with their supervisors and enthusiastically seek expert advice from their mentors in order to excel in professional sphere. Later investigations also endorsed that highly educated employees are better capable of maintaining positive, interactive, and stimulating relations with their supervisors (Altunoğlu \& Gürel, 2015); are prone to take initiatives in establishing positive leader-member relations (Xerri, 2013); tend to express augmented 
levels of work performance, innovative output, and moderate mechanisms of task execution (Taştan \& Davoudi, 2015).

Results of the present study further inferred that employees with extended job experience express better leader-member exchange, proactive behavior, and innovative work behavior. Prior literature provide substantial grounds in support of these findings; for instance, Chen (2011) reported that positive leadermember relationships are established when there is extended work experience; while Alsughayir (2017) found that employees with extensive work experience reflect better and active exchange with their leaders and elevated innovative work behavior at their workplaces. A reasonable explanation has been put forward by Yuan and Woodman (2010) stating that employees with extensive work experience acquire better skills to adjust and adapt in accordance to the organizational demands and perspectives which include both people and work context. In relation to proactive behavior, empirical evidence (Prahalad \& Ramaswamy, 2012) suggested that broader job skills and practices in the organization foster trust, proactive dynamism, and positive personal attributes which further enhances job satisfaction, job performance (Agarwal, 2014), and organizational citizenship behavior (Gan \& Chenug, 2010). Similarly, employees with greater occupational experience reflect elevated levels of proactivity, work related efficacy, and initiative-taking behaviors (Grant \& Ashford, 2008).

\section{LIMITATIONS AND SUGGESTIONS}

In the present study there are some potential limitations that should be cautiously dealt in the future studies. First, in the present study we adopted an employee-centered perspective and consider the quality of supervisor-employee relationship as perceived by employees. Secondly, the present study employed self report measures of leader-member exchange, proactive behavior and innovative work behavior; therefore there would be an element of social desirability. Thirdly, data was collected from only private sector software houses; hence there would be a lack of generalizability of findings. Finally, a cross sectional design of the present study may inhibit the causal relations among the variables. Therefore, in future endeavors, diverse organizational setups should be explored with longitudinal research design, so as to enhance the in-depth understanding of study variables.

\section{IMPLICATIONS}

The present study helps in understanding about the importance of proactive behavior, leadermember exchange and innovative work behavior in increasing productivity of the organizations. Leader-member exchange is one of the important components of almost every organization setting. Findings of the present study would facilitate in particular) and workplaces (in general) can be decreased by improving soft skills of managers and supervisors and by developing better leaderfollower interactions. Additionally, leadership and management practices should be improved so that conducive environment is formed to enhance innovative work behavior at the workplace and other job outcomes. Moreover, fostering positive proactive behavior would be effective in reducing interpersonal conflicts among employees. The study of innovative work behavior would assist in creating proactive attitude towards fresh technologies and developing new ways in software development.

\section{CONCLUSION}

Employees of software houses are interested in promoting and implementing new ideas. They actively over come challenging tasks and like all other organizations there is great potential in software houses' employees to stand out and surpass their competitors in achieving organizational goals. Our study clearly indicates that there is significantly positive relation between proactive behavior and enhanced leader-member relations with innovative work behavior. With extensive work experience and higher education level, employees showed more positive exchange with their leaders; are keen to take initiatives for developing new technologies and transforming new ideas into workable solutions. 


\section{REFERENCES}

[1] Agarwal, U. A. (2014). Linking justice, trust and innovative work behavior to work engagement. Journal of Personnel Review, 43(1), 41-73. https://doi.org/10.1108/pr-02-2012-0019

[2] Akram, T., Lei, S., \& Haider, M. J. (2016). The impact of relational leadership on employee innovative work behavior in IT industry of China. Arab Economic and Business Journal, 11(2), 153-161. https://doi.org/10.1016/j.aebj.2016.06.001

[3] Alsughayir, A. (2017). The effect of leader-member exchange on innovative work behavior in the Saudi hospitality sector. International Journal of Business and Management, 12 (6), 9383-9391. https://doi.org/10.5539/ijbm.v12n6p189

[4] Altunoğlu, A. E., \& Gürel, E. B. (2015). Effects of leader-member exchange and perceived organizational support on organizational innovation: The case of Denizli Technopark. Procedia-Social and Behavioral Sciences, 207, 175-181. https://doi.org/10.1016/j.sbspro.2015.10.170

[5] Bergeron, D. M., Schroeder, T. D., \& Martinez, H. A. (2014). Proactive personality at work: Seeing more to do and doing more? Journal of Business and Psychology, 29, 71-86. https://doi.org/10.1007/s10869-013-9298-5

[6] Bernerth, J. B., Walker, H. J., \& Harris, S. G. (2015). Rethinking the benefits and pitfalls of leader-member exchange: A reciprocity versus self-protection perspective. Human Relations, 69(3), 661-684. https://doi.org/10.1177/0018726715594214

[7] Chen, W. J., (2011). Innovation in hotel services: Culture and personality. International Journal of Hospitality Management, 30, 64-72. https://doi.org/10.1016/j.ijhm.2010.07.006

[8] Collins, M. D., (2007). Understanding the relationships between leader-member-exchange, psychological empowerment, job satisfaction, and turnover intent in a limited-service restaurant environment. (Unpublished Doctoral Dissertation), Graduate School of Management Sciences, Ohio State University, USA.

[9] Crant, J. M. (2000). Proactive behavior in organizations. European Journal of Work and Organizational Psychology, 5(4), 617-628. https://doi.org/10.1177/014920630002600304

[10] Cropanzano, R. \& Mitchell, M. (2005). Social exchange theory: An interdisciplinary review. Journal of Management, 31, 874-900. https://doi.org/10.1177/0149206305279602

[11] De Jong, J., \& Den Hartog, D. (2010). Measuring innovative work behaviour. Creativity and Innovation Management, 19(1), 23-36. https://doi.org/10.1111/j.1467-8691.2010.00547.x

[12] Frese, M., Garst, H. \& Fay, D. (2007). Making things happen: Reciprocal relationships between work characteristics and personal initiative in a four-wave longitudinal structural equation model. Journal of Applied Psychology, 92, 1084-1102. https://doi.org/10.1037/0021-9010.92.4.1084

[13] Fuller, B., \& Marler, L. E. (2009). Change driven by nature: A meta-analytic review of proactive personality literature. Journal of Vocational Behaviour, 75, 329-345. https://doi.org/10.1016/j.jvb.2009.05.008

[14] Gan, Y., \& Chenug, F. M. (2010). From proactive behavior to organizational citizenship behavior: mediating role of harmony. Psychological Reports, 106(3), 755-765. https://doi.org/10.2466/pr0.106.3.755-765

[15] Grant, A. M., \& Ashford, S. J. (2008). The dynamics of proactivity at work. Research in Organizational Behavior, 28, 3-34. https://doi.org/10.1016/j.riob.2008.04.002

[16] Janssen, O. (2000). Job demands, perceptions of effort-reward fairness, and innovative work behavior, Journal of Occupational and organizational psychology, 73, 287-302. https://doi.org/10.1348/096317900167038

[17] Kheng, Y. K., June, S., \& Mahmood, R. (2013). The determinants of innovative work behavior in the knowledge intensive business services sector in Malaysia. Asian Social Science, 9(15), 47-54. https://doi.org/10.5539/ass.v9n15p47

[18] Li, M., Gao, J., Wang, Z., \& Yu, X. (2016). Regulatory focus and teachers' innovative work behavior: The mediating role of autonomous and controlled motivation. Studies of Psychology and Behavior, 14, 42-50.

[19] Li, M., Wang, Z., Gao, J., \& Yu, X. (2015). Proactive personality and job satisfaction: the mediating effects of self-efficacy and work engagement in teachers. Current Psychology, 3(2), 18-26. https://doi.org/10.1007/s12144-015-9383-1

[20] Lo, M, C., Ramayah, T., \& Run, E, C. (2009). Leader-member exchange, gender and influence tactic: A test on multinational companies of Malaysia. Problems and Perspectives in Management, 7 (1), 49-56.

[21] Lunenburg, F, C. (2010). Leader-member exchange theory: Another perspective on the leadership process. International Journal of Management, Business, and Administration, 13, (1), 1-5. https://doi.org/10.4135/9781452276090.n151 
[22] Prahalad, C. K., \& Ramaswamy, V. (2012). The new frontier of experience innovation. New York: Image. https://doi.org/10.1109/wnyipw31050.2012

[23] Schyns, B., Paul, T., Mohr, G., \& Blank, H. (2005). Comparing antecedents and consequences of LMX in German working context to findings in the US. European Journal of Work and Organizational Psychology, 14, 1-22. https://doi.org/10.1080/13594320444000191

[24] Seibert, S. E., Kraimer, M. L., \& Crant, J. M., (2001). What do proactive people do? A longitudinal model linking proactive personality and career success. Personnel Psychology, 54(4), 845-874. https://doi.org/10.1111/j.1744-6570.2001.tb00234.x

[25] Suhaimi, I. W., \& Panatik, S. A. (2016). A literature review on relationship between leader-member exchange and innovation work behavior. Journal of Global Business and Social Entrepreneurship, 1(2), 32-41.

[26] Tastan, S. B. (2013). The influences of participative organizational climate and self-leadership on innovative behavior and the roles of job involvement and proactive personality: A survey in the context of SMEs in Izmir. Technology and Innovation Management, 75, 407 - 419. https://doi.org/10.1016/j.sbspro.2013.04.045

[27] Taştan, S. B., \& Davoudi, S. M. M. (2015). An examination of the relationship between leader-member exchange and innovative work behavior with the moderating role of trust in leader: A study in the Turkish context. Procedia - Social and Behavioral Sciences, 181(1), 23-32. https://doi.org/10.1016/j.sbspro.2015.04.862

Received on 19-01-2020

Accepted on 30-01-2020

Published on 10-02-2020

(C) 2020 Aisha Zubair and Naeem Aslam; Licensee ATSK Publishers.

This is an open access article licensed under the terms of the Creative Commons Attribution Non-Commercial License (http://creativecommons.org/licenses/by-nc/3.0/) which permits unrestricted, noncommercial use, distribution and reproduction in any medium, provided the work is properly cited. 